\title{
Large cystic lymphangioma of pancreas mimicking mucinous neoplasm: case report with a review of histological differential diagnosis
}

This article was published in the following Dove Press journal: International Medical Case Reports Journal

\author{
Mohammad Hossein \\ Anbardar (D) ${ }^{1,2}$ \\ Neda Soleimani ${ }^{1,2}$ \\ Arian Aminzadeh Vahedi' \\ Seyed Ali Malek-Hosseini ${ }^{2,3}$ \\ 'Department of Pathology, Shiraz Medical \\ School, Shiraz University of Medical \\ Sciences, Shiraz, Iran; ${ }^{2}$ Shiraz Transplant \\ Center, Abu Ali Sina Hospital, Shiraz \\ University of Medical Sciences, Shiraz, \\ Iran; ${ }^{3}$ Department of Surgery, Abualisina \\ Hospital, Shiraz Medical School, Shiraz \\ University of Medical Sciences, Shiraz, \\ Iran
}

Correspondence: Mohammad Hossein Anbardar

Department of Pathology, Shiraz Medical School, Shiraz University of Medical Sciences, PO Box 7I345-1864, Shiraz, Iran

Tel +987132301784

$\mathrm{Fax}+987132301784$

Email anbardarm@sums.ac.ir
Purpose: Cystic lymphangioma of the pancreas was first recognized in 1913 as a form of benign cyst. It is extremely rare, accounting for less than $1 \%$ of the lymphangiomas.

Case report: Herein, we report a case of cystic pancreatic lymphangioma diagnosed in a 51-year-old female patient who was hospitalized for a colicky upper abdominal pain for a month. Radiological imaging revealed a large multiloculated cystic pancreatic mass with enhancing septations. The patient underwent distal pancreatectomy, and the histological examination showed cystic lymphangioma.

Conclusion: Although very uncommon, cystic lymphangioma should be placed in the differential diagnosis list of pancreatic cystic lesions, at least about the multi-septated ones in asymptomatic female patients which are discovered incidentally.

Keywords: pancreas, lymphangioma, histopathology, cystic lesion, benign

\section{Background}

Lymphangioma is a benign cystic malformation of the lymphatic vessels that usually occur in the children's head and neck area. The abdominal organs are a rare site for cystic lymphangioma, and the pancreas is also a very rare site of origin. $^{1-3}$ We would like to report a 51-year-old female case with a large cystic lymphangioma of the pancreas misdiagnosed as mucinous cystic neoplasm in radiology and review the histological differential diagnoses.

\section{Case report}

A 51-year-old woman presented with colicky upper abdominal pain for a month. The patient had a medical history that included diabetes mellitus, hypothyroidism (taking medication for them) and hysterectomy (2 years earlier). There was no history of jaundice, weight loss, and loss of appetite. Personal and social history was noncontributory. General physical examination was unremarkable, and her abdomen was soft without any tenderness or mass palpation. Laboratory investigation just showed uncontrolled blood sugar and mild elevation of liver enzymes. Abdominal sonography showed a lobulated and multicystic mass in the retroperitoneum and at the site of the body and tail of the pancreas. Spiral CT scan and MRI of the abdomen revealed a large well-defined multiloculated cystic mass, measuring $11 \times 10 \mathrm{~cm}$ with fine septation in the body and tail of the pancreas without any connection to the pancreatic duct, suspicious for a mucinous cystadenoma (Figure 1). The patient underwent distal 


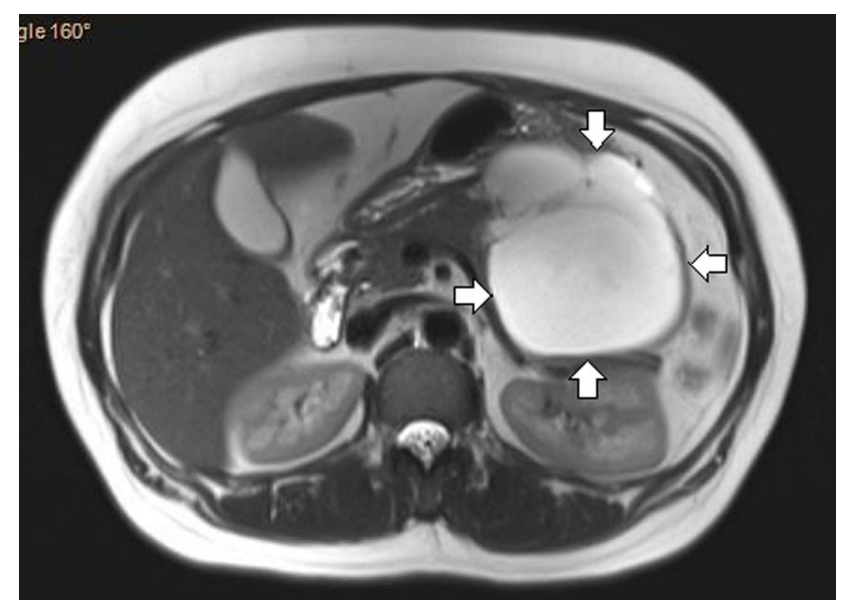

Figure I MRI view of the abdomen shows large multicystic mass in the body and tail of the pancreas with enhancement.

pancreatectomy and splenectomy. Splenectomy with preoperative immunization was done due to the assurance of complete excision of the mass. On pathologic examination, grossly there was a multiloculated gray cystic mass in the body and tail of the pancreas, filled with brown watery fluid (Figure 2). Histological examination showed multiple large irregular cystic spaces lined by the endothelial cells with pinkish smooth fluid in the lumen and extensive lymphoid aggregation and lymphoid follicles between them, consisting of cystic lymphangioma (Figure 3 ). The patient is well without any complication after about 3 months postoperatively. A written informed consent has been provided by the patient for publishing the case report and the publication of

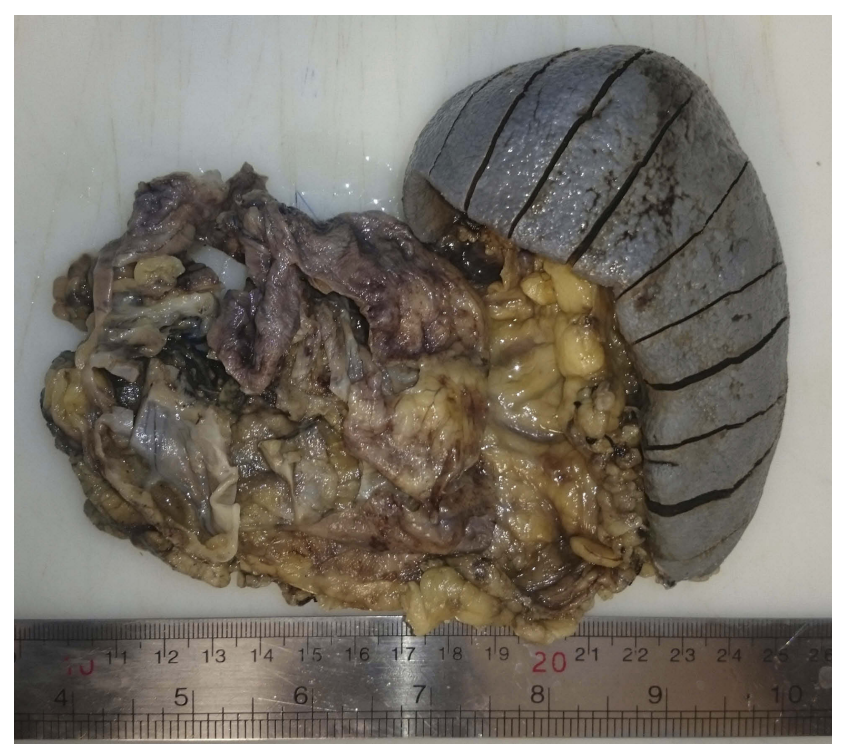

Figure 2 Gross examination shows already opened cystic mass of the pancreas.

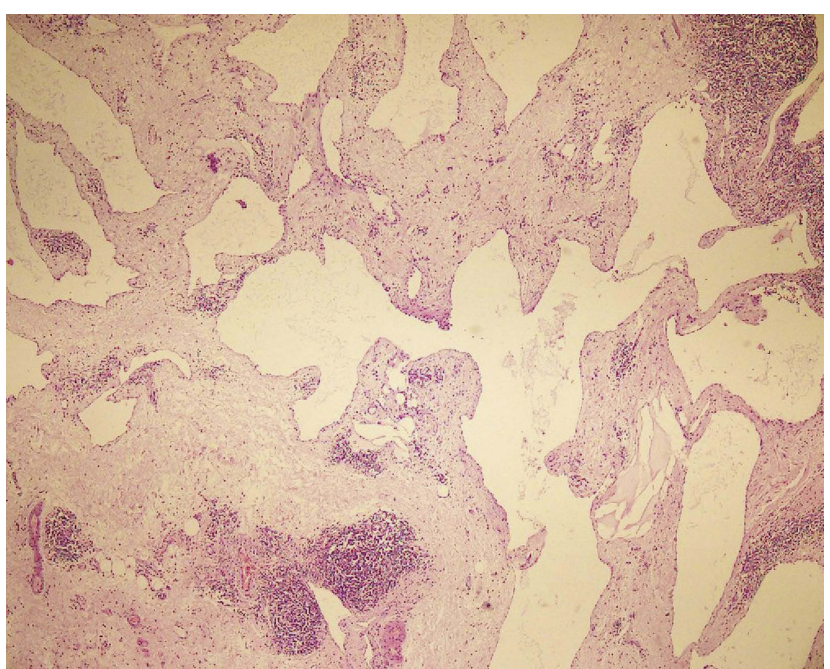

Figure 3 Microscopic section shows large and dilated lymphatic channels lined with thin endothelium and lymphoid aggregates in the septa. (H\&E, $\times 100)$.

the accompanying images. Also, our institutional approval is not required to publish the case details.

\section{Discussion}

Lymphangioma is a malformation of the lymphatic system that usually involves young children. Different mechanisms of lymphangioma include failure of the lymphatic system to connect with or separate from the venous system and abnormal budding of the lymphatic system from the cardinal vein. It could also be secondary due to infections, chronic inflammations, obstructions, trauma, and radiological treatment, but the exact underlying cause is unknown in most cases. Recently, the possible impact of lymphangiogenic growth factors on the development of lymphangiomas has been discussed. ${ }^{1-3}$

The most frequently reported sites are the head and neck (75\%), axilla (20\%), and other organs $(5 \%){ }^{2}$ Abdominal lymphangiomas are rare benign cystic tumors that can become locally invasive and often require resection. Most tumors were located in the mesenteric region, and less frequently in the mesocolic, greater omental, and retroperitoneal regions, the small intestinal and gastric walls, and the peritoneum. A variety of other sites have been described including the mediastinum, pleura, pericardium, groin, bones, and abdomen. In the abdomen, the mesentery and retroperitoneum are the most common sites. ${ }^{4}$ Cystic lymphangioma of the pancreas was first identified in 1913 by Koch as a form of benign cyst. It is extremely rare, accounting for less than $1 \%$ of lymphangiomas. Frequently occurring in the pancreatic tail, the disease is reported more often in females in all age groups. ${ }^{5}$ 
Although often asymptomatic, they can present with a palpable abdominal mass and non-specific gastrointestinal symptoms such as abdominal pain and nausea/ vomiting. ${ }^{6}$ Pancreatic pseudocyst, hydatid cyst, serous and mucinous cystadenoma, intraductal papillary mucinous neoplasm, congenital cyst, rare pancreatic ductal carcinoma (cystic carcinoma of the Wirsung's Duct), and congenital neoplasms are among the differential diagnosis of pancreatic lymphangioma. ${ }^{4}$ For distinction between cystic lymphangioma and other differentials, diagnostic tools such as plain abdominal films, abdominal CT, and MRI may be helpful. Plain abdominal Xrays may show dislocation of the intestines, and $\mathrm{CT}$ and MRI could help determine the preoperative location of the mass, and assist determining the possibility of communication between the mass and an adjacent structure, the size of the mass and likely complications of the surgery. However, these modalities do not assure a completely precise diagnosis. It is still considered a difficult task to exactly diagnose pancreatic cystic lymphangioma before a surgical procedure, ${ }^{4,5}$ but the final diagnosis is just made by tissue examination. ${ }^{7}$

Histologically, there are 3 types of lymphangioma (capillary, cavernous, and cystic). Lymphangiomas may be composed of small and large communicating cysts (cystic lymphangioma) or sponge-like areas composed of small cavernous spaces (cavernous lymphangioma). Subclassification into capillary, cavernous, or cystic types based on the vessel size is of no clinical significance and is no longer recommended. ${ }^{8}$

Histologically, there are many differential diagnoses when we have a benign pancreatic cystic lesion. Pseudocysts are the most common type of cystic lesions of the pancreas; there is no epithelial lining, and the adjacent stroma may be hypercellular and may mimic ovariantype stroma. Any epithelial component within the cyst wall suggests an alternative diagnosis to pseudocyst. ${ }^{9,10}$

Intraductal papillary mucinous neoplasms (IPMNs) were thought to be very rare, but in recent years, better identification of this neoplasm has led to an increase in its known incidence. Microscopically, papillae with 3 distinct morphologic patterns can be seen: Gastric-foveolar or null type, villous-intestinal type, and pancreatobiliary type. ${ }^{10,11}$

Mucinous cystic neoplasms (MCN) are supposedly de novo cystic tumors seen almost solely in perimenopausal female patients and mostly appear in the body or tail of the pancreas. MCNs are composed of thick-walled multilocular cysts that can become very large. Microscopically, the cysts are lined by tall, columnar, mucin-producing epithelium that is similar to endocervical epithelium. ${ }^{10,12}$ In Table 1 , the characteristics of pancreatic mucinous neoplasm and cystic lymphangioma are presented.

Serous cystadenoma (SCA) is a benign neoplasm composed of uniform glycogen-rich epithelial cells that form countless small cysts containing serous fluid. Nearly, two-thirds of SCAs arise in the body-tail region of the pancreas and are seen prevalently in female patients. The lesions usually present as large masses and the cut surface shows numerous, tightly packed, small, thin-walled cysts (spongelike or honeycomb appearance) organized around a central stellate scar. Microscopically, the single layer of cuboidal or flattened cells lining the small cysts has well-defined cytoplasmic borders, pale to clear cytoplasm, and small, round uniform nuclei with dense, homogeneous chromatin and inconspicuous nucleoli. ${ }^{10,13}$

Lymphoepithelial cysts are multilocular $(60 \%)$ or unilocular (40\%) cystic lesions mostly seen in older adults with a male predominance. They can be seen in any component of the pancreas and often project into the peripancreatic tissues. Microscopically, the cysts are lined by well-differentiated stratified squamous epithelium, usually with keratinization. $^{10}$

Rarely, hydatid cysts, necrotic tuberculosis infections, and other entities can occur in the pancreas and mimic primary cystic neoplasms. ${ }^{10}$

The majority of cystic tumors of the pancreas are slow-growing and asymptomatic. Several studies reported that no imaging studies are adequately accurate to differentiate between the benign, premalignant, and malignant lesions. ${ }^{14,15}$ Percutaneous or endoscopic aspiration has the potential to spill malignant cells with the possibility of reducing survival, so it is not usually recommended to use these invasive and expensive diagnostic procedures. ${ }^{15}$ In the absence of a good radiologic or pathologic test to preoperatively determine the diagnosis, clinical characteristics such as age, gender, the presence of symptoms, cyst size, or location might be helpful. ${ }^{14}$ No specific symptom was meaningfully associated with the possibility of malignancy although increasing anorexia, jaundice, and weight loss (10-40\%) may be associated with malignant changes. ${ }^{16,17}$ Older patients are more likely to have premalignant or malignant cystic pancreatic neoplasms. The overall incidence of malignancy is higher in men. ${ }^{15}$ High values of CEA and CA 19-9 show a high positive predictive value for pancreatic malignancy or pre- 
Table I Comparison of characteristics of pancreatic mucinous neoplasm and cystic lymphangioma

\begin{tabular}{|c|c|c|}
\hline & Pancreatic mucinous neoplasm & Pancreatic cystic lymphangioma \\
\hline Epidemiology & $\begin{array}{l}\text { In middle-aged female }{ }^{10} \\
\text { Female to male ratio } 20: 1^{24} \\
\text { An incidence rate of } 2.4 \% \text { and a prevalence rate of } 2.6 \%^{24} \\
10-15 \% \text { of all pancreatic cystic lesions and less than } 1 \% \text { of } \\
\text { pancreatic tumors }{ }^{18}\end{array}$ & $\begin{array}{l}\text { More often in females, with a similar incidence across all age } \\
\text { groups } \\
\text { Less than } 1 \% \text { of lymphangiomas } \\
\text { less than } 0.2 \% \text { of all pancreatic cysts }{ }^{5,28}\end{array}$ \\
\hline Pathophysiology & $\begin{array}{l}\text { Etiology: unclear } \\
\text { Related to female hormones }\end{array}$ & Blockage in regional lymph ducts \\
\hline $\begin{array}{l}\text { Clinical } \\
\text { manifestation }\end{array}$ & $\begin{array}{l}\text { Abdominal pain }(62.2 \%) \text {, weight loss }(11 \%) \text {, abdominal mass } \\
\text { (1 } 1 \%) \text {, acute pancreatitis }(9.6 \%) \text {, fatigue }(8.9 \%) \text {, and } 16 \% \\
\text { asymptomatic }^{26}\end{array}$ & $\begin{array}{l}\text { Often asymptomatic, or palpable abdominal mass and } \\
\text { nonspecific gastrointestinal symptoms such as abdominal } \\
\text { pain and nausea/vomiting }\end{array}$ \\
\hline $\begin{array}{l}\text { Radiological } \\
\text { findings }\end{array}$ & $\begin{array}{l}\text { Unilocular or multilocular single macrocyst with a solid } \\
\text { component, with no communication with the main duct } \\
\text { More frequent cyst wall calcification, focal thickening of the cyst } \\
\text { wall and papillary projections }{ }^{27}\end{array}$ & $\begin{array}{l}\text { Well-circumscribed, encapsulated, water-isodense, uni or } \\
\text { multilocular lesions with thin septa }{ }^{29}\end{array}$ \\
\hline Gross findings & $\begin{array}{l}\text { Mostly }(93 \%) \text { in the body or tail of the pancreas } \\
\text { Median size: } 5 \mathrm{~cm} \\
\text { Solitary, multilocular or unilocular lesions }{ }^{10}\end{array}$ & $\begin{array}{l}\text { Frequently occurring in the pancreatic body and tail } \\
\text { Tumor size is variable } \\
30\end{array}$ \\
\hline $\begin{array}{l}\text { Histological } \\
\text { findings }\end{array}$ & $\begin{array}{l}\text { Two distinct histologic components: inner epithelial layer composed } \\
\text { of tall mucin-secreting cells (different grades of dysplasia: mild, } \\
\text { moderate and severe), and dense cellular ovarian stroma } \\
\text { No communication with the pancreatic ductal system }{ }^{10,12}\end{array}$ & $\begin{array}{l}\text { Dilated cystic spaces lined by endothelial cells and containing } \\
\text { proteinaceous eosinophilic fluid }\end{array}$ \\
\hline Treatment & Surgical resection & Surgical resection \\
\hline Prognosis & $\begin{array}{l}\text { In the absence of invasive carcinoma: excellent }{ }^{18} \\
\text { Cystadenocarcinoma: } 5 \text {-year survival rate of } 20-60 \%^{18}\end{array}$ & $\begin{array}{l}\text { Very low chance of recurrence and the overall prognosis is } \\
\text { excellent }\end{array}$ \\
\hline
\end{tabular}

malignancy in the preoperative assessment of pancreatic cystic mass $(70-100 \%){ }^{16,18}$ The presence of a solid component, invading outside the pancreas, or pancreatic duct obstruction through endoscopic ultrasound is highly indicative of malignancy. ${ }^{15,19-21}$ Some authors suggest that the size of the cystic lesion is an indicator of its malignant potential, lesions larger than $2 \mathrm{~cm}$ in size merit aggressive management due to the higher risk of malignant potential. ${ }^{17,22,23}$

The treatment of choice of pancreatic lymphangioma is complete surgical resection with a very low chance of recurrence and the overall prognosis is excellent. ${ }^{31}$ Partial resection is associated with a high recurrence rate, 50\% in one series after a mean follow-up period of 2 years. Although lymphangioma is a benign tumor, it often behaves in an aggressive manner and can grow to an enormous size. Therefore, resection of the adjacent organs may be required to accomplish complete excision. $^{32}$

\section{Conclusion}

Although very uncommon, cystic lymphangioma should be placed in the differential diagnosis list of pancreatic cystic lesions, at least about the multiseptated ones in asymptomatic female patients, which are discovered incidentally. Clinical and radiological characteristics are not helpful in preoperative diagnosis of pancreatic lymphangioma and differentiation with mucinous neoplasm. Pathological examination is necessary for definite diagnosis.

\section{Acknowledgment}

The authors would like to thank Shiraz University of Medical Sciences, Shiraz, Iran, and Center for Development of Clinical Research of Nemazee Hospital and Dr. Nasrin Shokrpour for editorial assistance.

\section{Disclosure}

The authors report no conflicts of interest in this work. 


\section{References}

1. Wiegand S, Eivazi B, Barth PJ, et al. Pathogenesis of lymphangiomas. Virchows Arch. 2008;453(1):1-8. doi:10.1007/s00428-008-0611-z

2. Losanoff JE, Richman BW, El-Sherif A, Rider KD, Jones JW. Mesenteric cystic lymphangioma. J Am Coll Surg. 2003;196 (4):598-603. doi:10.1016/S1072-7515(02)01755-6

3. Allen JG, Riall TS, Cameron JL, Askin FB, Hruban RH, Campbell KA. Abdominal lymphangiomas in adults. $J$ Gastrointest Surg. 2006;10(5):746-751. doi:10.1016/j.gassur.2005.10.015

4. Mousavi SR, Moradi A, Sobhiyeh MR, et al. A patient with cystic lymphangioma in pancreas. Gastroenterol Hepatol Bed Bench. 2013;6(3):159-164.

5. Colovic RB, Grubor NM, Micev MT, Atkinson HD, Rankovic VI, Jagodic MM. Cystic lymphangioma of the pancreas. World $J$ Gastroenterol. 2008;14(44):6873-6875. doi:10.3748/wjg.14.6873

6. Black T, Guy CD, Burbridge RA. Retroperitoneal cystic lymphangioma diagnosed by endoscopic ultrasound-guided fine needle aspiration. Clin Endosc. 2013;46(5):595-597. doi:10.5946/ce.2013.46.5.595

7. Igarashi A, Maruo $\mathrm{Y}$, Ito $\mathrm{T}$, et al. Huge cystic lymphangioma of the pancreas: report of a case. Surg Today. 2001;31(8):743-746. doi: $10.1007 / \mathrm{s} 005950170084$

8. Schneider G, Seidel R, Altmeyer K, et al. Lymphangioma of the pancreas and the duodenal wall: MR imaging findings. Eur Radiol. 2001;11(11):2232-2235. doi:10.1007/s003300100846

9. Klöppel G. Pseudocysts and other non-neoplastic cysts of the pancreas. Semin Diagn Pathol. 2000;17(1):7-15.

10. Basturk O, Coban I, Adsay NV. Pancreatic cysts: pathologic classification, differential diagnosis, and clinical implications. Arch Patho Lab Med. 2009;133(3):423-438. doi:10.1043/1543-2165-133.3.423

11. Adsay NV. The "new kid on the block": intraductal papillary mucinous neoplasms of the pancreas: current concepts and controversies. Surgery. 2003;133(5):459-463. doi:10.1067/msy.2003.127

12. Albores-Saavedra J, Gould EW, Angeles-Angeles A, Henson DE. Cystic tumors of the pancreas. Pathol Annu. 1990;25 Pt 2:19-50.

13. Compton CC. Serous cystic tumors of the pancreas. Semin Diagn Pathol. 2000;17(1):43-55.

14. Spinelli KS, Fromwiller TE, Daniel RA, et al. Cystic pancreatic neoplasms: observe or operate. Ann Surg. 2004;239:651-657. doi:10.1097/01.sla.0000124299.57430.ce

15. Atef E, El Nakeeb A, El Hanafy E, El Hemaly M, Hamdy E, ElGeidie A. Pancreatic cystic neoplasms: predictors of malignant behavior and management. Saudi J Gastroenterol. 2013;19(1):45-53. doi:10.4103/1319-3767.105927

16. Garcea G, Ong SL, Rajesh A, et al. Cystic lesions of the pancreas. A diagnostic and management dilemma. Pancreatology. 2008;8(3):236251. doi:10.1159/000134279

17. Fernandez-del Castillo C, Targarona J, Thayer SP, Rattner DW, Brugge WR, Warshaw AL. Incidental pancreatic cysts: clinicopathologic characteristics and comparison with symptomatic patients. Arch Surg. 2003;138(4):427-423. discussion 433-424. doi:10.1001/ archsurg.138.4.427
18. Naveed S, Qari H, Banday T, Altaf A, Para M. Mucinous cystic neoplasms of pancreas. Gastroenterol Res. 2014;7(2):44-50. doi:10.14740/gr600e

19. Sahani DV, Kadavigere R, Saokar A, Fernandez-del Castillo C, Brugge WR, Hahn PF. Cystic pancreatic lesions: a simple imagingbased classification system for guiding management. Radiographics. 2005;25(6):1471-1484. doi:10.1148/rg.256045161

20. Lee CJ, Scheiman J, Anderson MA, et al. Risk of malignancy in resected cystic tumors of the pancreas $\leq 3$ or $=\mathrm{cm}$ in Size: is it safe to observe asymptomatic patients? A multi-institutional report. $J$ Gastrointest Surg. 2008;12:234-242. doi:10.1007/ s11605-007-0381-y

21. Javle M, Shah P, Yu J, et al. Cystic Pancreatic Tumors (CPT): predictors of malignant behavior. J Surg Oncol. 2007;95:221-228. doi: $10.1002 /$ jso. 20648

22. Silas AM, Morrin MM, Raptopoulos V, Keogan MT. Intraductal papillary mucinous tumours of the pancreas. AJR. 2001;176:179185. doi:10.2214/ajr.176.1.1760179

23. Sarr MG, Kendrick ML, Nagorney DM, Thompson GB, Farley DR, Farnell M. Cystic neoplasm of the pancreas: benign to malignant epithelial neoplasms. Surg Clin North Am. 2001;81:497-509. doi:10.1016/s0039-6109(05)70139-0

24. Choi JH, Seo DW, Song TJ, et al. Long-term outcomes after endoscopic ultrasound-guided ablation of pancreatic cysts. Endoscopy. 2017;49(9):866-873. doi:10.1055/s-0043-110030

25. Pak LM, D'Angelica MI, DeMatteo RP, et al. Natural history of patients followed radiographically with mucinous cysts of the pancreas. J Gastrointest Surg. 2017;21(10):1599-1605. doi:10.1007/ s11605-016-3338-1

26. Joshi U, Poudel P, Ghimire RK, Basnet B. Pancreatic pseudocyst or mucinous cystadenocarcinoma of pancreas? A diagnostic dilemma. Clin Case Rep. 2017;5(4):501-504. doi:10.1002/ccr3.887

27. Leung TK, Lee CM, Shen LK, Chen YY. Differential diagnosis of cystic lymphangioma of the pancreas based on imaging features. $J$ Formos Med Assoc. 2006;105(6):512-517. doi:10.1016/S0929-6646 (09)60193-5

28. Carvalho D, Costa M, Russo P, Simas L, Baptista T, Ramos G. Cystic pancreatic lymphangioma - Diagnostic role of endoscopic ultrasound. GE Port J Gastroenterol. 2016;23(5):254-258. doi:10.1016/j. jpge.2016.01.006

29. Viscosi F, Fleres F, Mazzeo C, Vulcano I, Cucinotta E. Cystic lymphangioma of the pancreas: a hard diagnostic challenge between pancreatic cystic lesions-review of recent literature. Gland Surg. 2018;7(5):487-492. doi:10.21037/gs.2018.04.02

30. Sohn BK, Cho CH, Chae HD. Cystic lymphangioma of the pancreas. $J$ Korean Surg Soc. 2011;81(2):141-145. doi:10.4174/jkss.2011.81.2.141

31. Cherk M, Nikfarjam M, Christophi C. Retroperitoneal lymphangioma. Asian J Surg. 2006;29(1):51-54. doi:10.1016/S1015-9584 (09)60297-9

32. Dalla Bona E, Beltrame V, Blandamura S, Liessi F, Sperti C. Huge cystic lymphangioma of the pancreas mimicking pancreatic cystic neoplasm. Case Rep Med. 2012;2012:951358. doi:10.1155/2012/ 951358

International Medical Case Reports Journal

Dovepress

\section{Publish your work in this journal}

The International Medical Case Reports Journal is an international, peer-reviewed open-access journal publishing original case reports from all medical specialties. Previously unpublished medical posters are also accepted relating to any area of clinical or preclinical science. Submissions should not normally exceed 2,000 words or 4

published pages including figures, diagrams and references. The manuscript management system is completely online and includes a very quick and fair peer-review system, which is all easy to use. Visit http://www.dovepress.com/testimonials.php to read real quotes from published authors. 